\title{
Bladder Lipoma Associated with Urinary Tract Infection
}

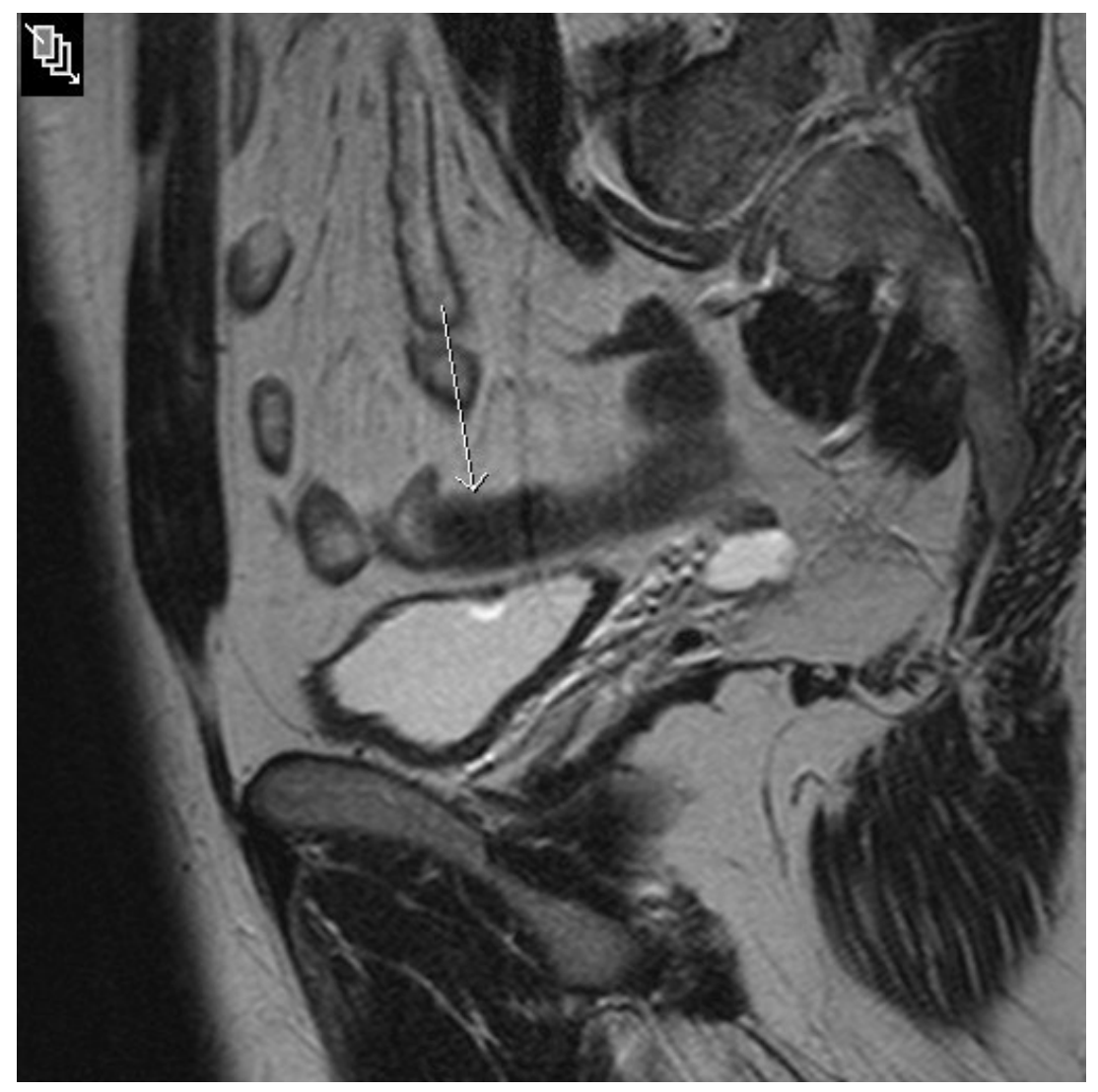

Christopher Brown* and Adam Jones

Royal Berkshire Hospital, Harold Hopkins Department of Urology, Reading, U.K.

E-mail: CNBROWN@doctors.org.uk

Received April 2, 2008; Revised May 12, 2008; Accepted June 2, 2008; Published June 13, 2008

Lipomas are benign overgrowths of adipose tissue. They are an unusual finding within the bladder wall. There have been five reports[1,2] of bladder lipomas associated with micro- and macroscopic haematuria. We report, to our knowledge, the first bladder lipoma associated with a microbiologically confirmed urinary tract infection.

KEYWORDS: bladder, lipoma, infection 
A 44-year-old man presented to the urology outpatient department following a first proven urinary tract infection. Culture of the urine confirmed an E. coli organism. The patient had a history of renal calculi 9 years previously (which had passed spontaneously), but was otherwise fit and well. He underwent an ultrasound scan of his renal tract, which was normal. At flexible cystoscopy, a benign-looking submucosal polyp within the dome of the bladder was seen. The patient subsequently had an MRI scan of the pelvis (see image), which demonstrated this lesion, but no additional abnormalities. This was resected at cystoscopy under general anaesthesia and histological analysis confirmed the mass to be benign adipose tissue (lipoma). We believe this is the first reported case of a bladder lipoma associated with a microbiologically confirmed urinary tract infection.

\section{REFERENCES}

1. $\quad$ Eggener, S.E. et al. (2001) Bladder lipoma. J. Urol. 166, 1395.

2. Lang, E.K. (2005) Symptomatic bladder lipomas. J. Urol. 174, 313.

This article should be cited as follows:

Brown, C. and Jones, A. (2008) Bladder lipoma associated with urinary tract infection. TheScientificWorldJOURNAL: TSW Urology 8, 573-574. DOI 10.1100/tsw.2008.91. 


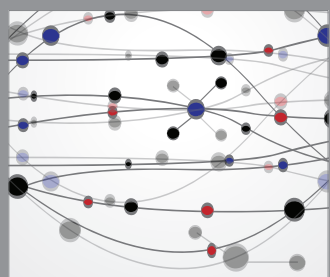

The Scientific World Journal
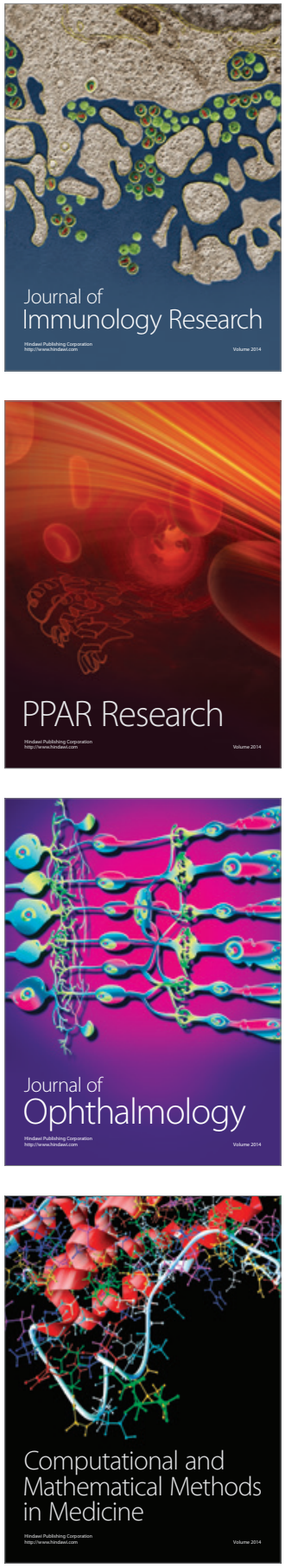

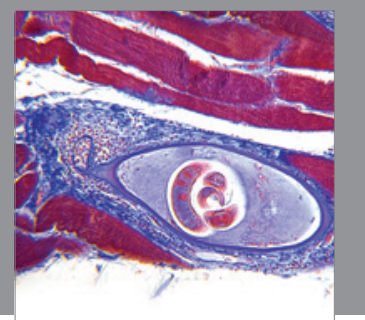

Gastroenterology

Research and Practice
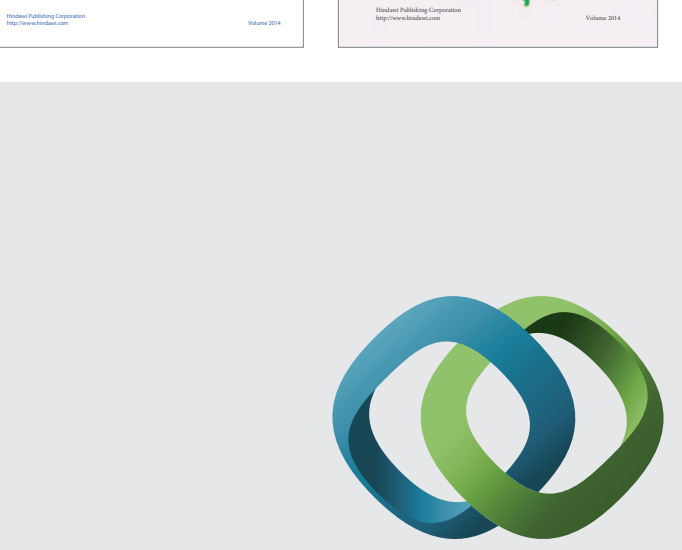

\section{Hindawi}

Submit your manuscripts at

http://www.hindawi.com
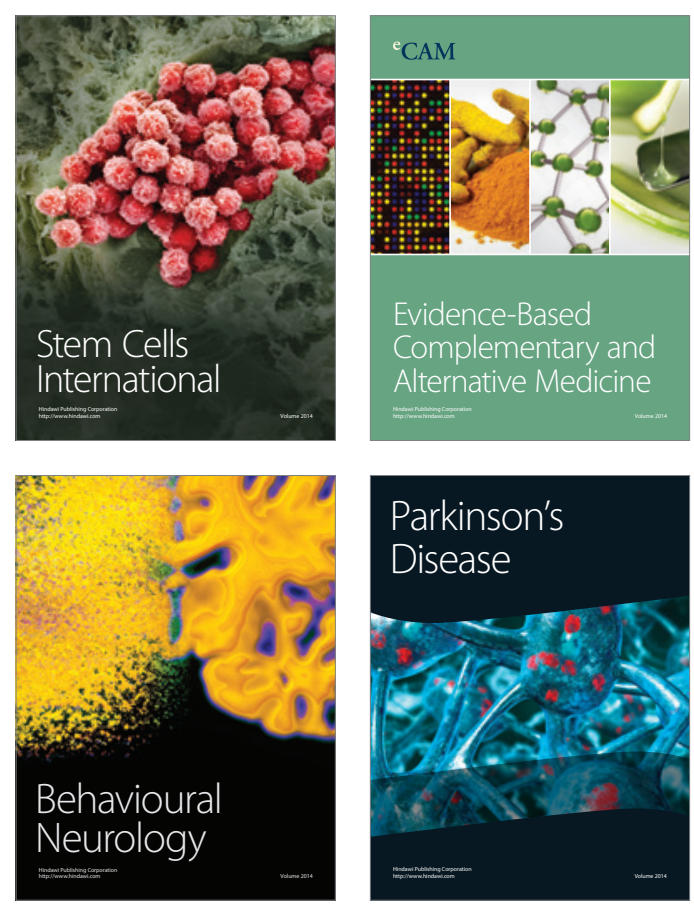

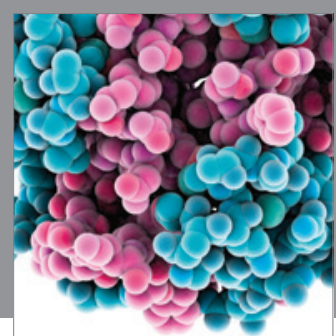

Journal of
Diabetes Research

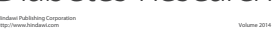

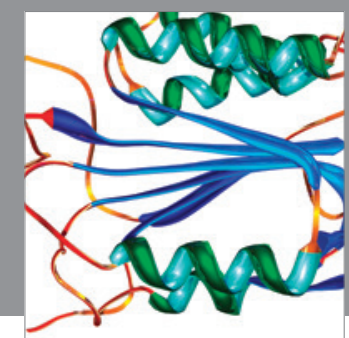

Disease Markers
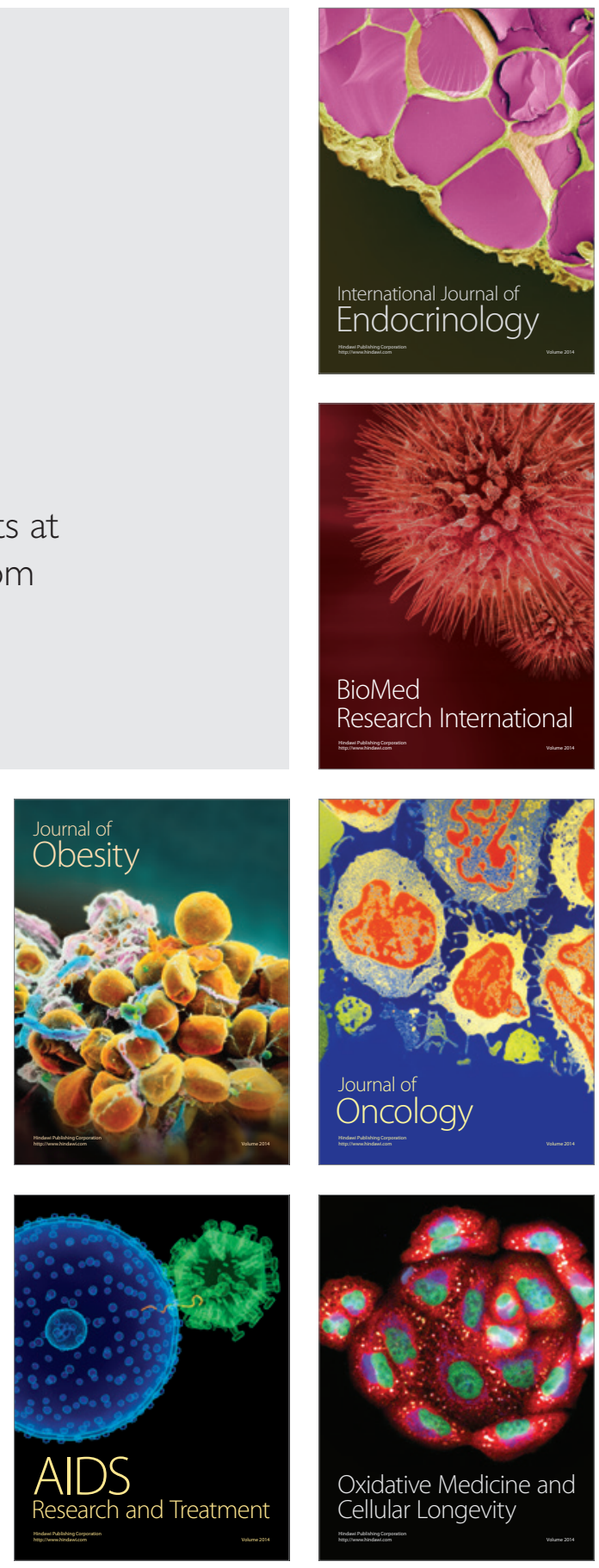